\title{
Mass Fraction
}

National Cancer Institute

\section{Source}

National Cancer Institute. Mass Fraction. NCI Thesaurus. Code C67470.

Quotient of the mass of a component and the total mass of the system containing the component. For clinical chemistry the term component is recommended, ISO uses substance. For clinical chemistry the term system is recommended, ISO uses mixture. 